\title{
SAURAYUTHAH: SPACE SETTLEMENT IN THE FUTURE
}

\author{
Avyaan Gulati ${ }^{1}$, Shivank Kapur ${ }^{2}$, Gopesh Bajaj ${ }^{3}$, Vatsal Gupta ${ }^{4}$ and Kanav Goyal ${ }^{5}$ \\ ${ }^{1}$ St. Columba's School, New Delhi \\ 2,3,4,5 venkateshwar global school
}

DOI: 10.46609/IJSSER.2021.v06i07.021 URL: https://doi.org/10.46609/IJSSER.2021.v06i07.021

\begin{abstract}
The settlement is named after the Sanskrit word - sauray meaning solar and - uthah as system. To sum up, we named our settlement with ancient connections to the prehistoric time where Sanskrit being one of the primary languages during the early time of predictions of space research and exploration, but also connects it to the modern era and suggesting crucial evidence that history connected with the present helps predict the future.

The prime location of our space settlement being over the asteroid belt between Mars and Jupiter also marks one of the reasons as naming it after the SOLAR SYSTEM.

Connecting our roots with the future will surely help us learn more about different cultures and initiate the process towards better and faster research in the field of space exploration.
\end{abstract}

\section{INTRODUCTION}

\section{The Asteroid Region}

The asteroid, our spaceship would be around is 16 psyche, which is an M-type asteroid placed between Mars and Jupiter, the asteroid is predominantly metal including precious metals as well as adequate amounts of water.

Metals such as platinum, gold and others such as nickel, iron. The asteroid 370million kilometers away from earth has enough iron to fill the whole city of Manhattan and is estimated to be around $\$ 10$ Quadrillion which is more than the whole economy of earth, although the information on its full composition is tobe revealed by the year 2022 .

There are already scientists determined to find the age and origins of the mammoth metallic asteroid. Missions to visit the asteroid by 2022 are also in full take. 
When it comes to the asteroid dimensions, it has a Radius of about $113 \mathrm{~km}$, mass of around $2.72 \times 10^{\wedge} 19 \mathrm{~kg}$ and also has a day of 4.196 earth hours and has an Orbital Period of about five Earth years.

As we know that the contents of an asteroid do not determine its actual value but the profit and other benefits it provides. Not only is this asteroid being targeted by spaceX in 2022 , it will also provide more details about the nearby life of the project and further prospectus of development and research in the area.

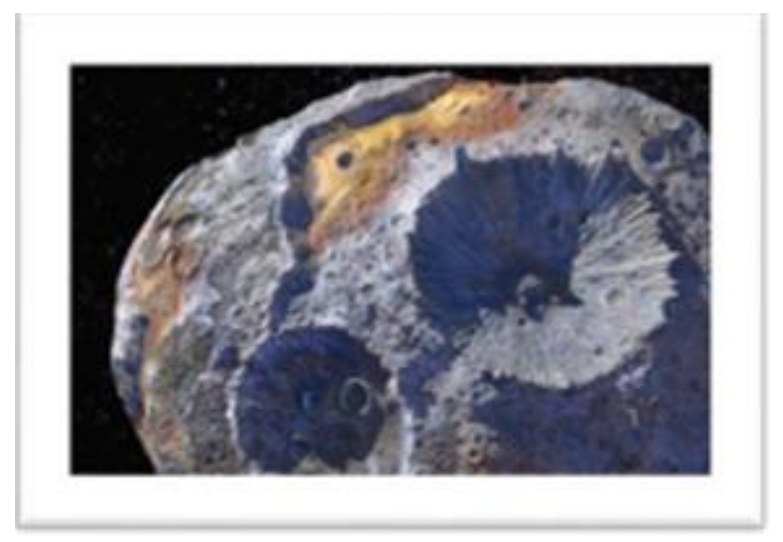

Along with space mining, this asteroid also suits as a prime spot for further space exploration in and around the asteroid belt. Enough for funding the entire mission and also aligning space exploration is what makes it a golden and rare opportunity towards reaching out our goals about space exploration.

The resources and water there will also help the space settlement to run as well as make it a complete self-sustained ecosystem.

\section{TECHNOLOGY REVIEW \& ANALYSIS}

\section{OUR SPACE SETTLEMENT STATION'S DESIGN}

\section{Structural Design}

The design has been undermined in accordance with modern technical know-how and its usage.

It is a framework of simple yet effective paradigms. The following factors have been taken into consideration before the designing work was taken into consideration

1. Self-sustainable

2. Agriculture and mining provisions 


\section{International Journal of Social Science and Economic Research}

ISSN: 2455-8834

Volume:06, Issue:07 "July 2021"

3. Lodging and accommodation of over 500 people and staff members.

4. Pre-installed emergency/search out pods for space exploration and mining search are not only restricted to nearby places.

5. A direct approach towards space exploration as the location is promising forfurther research.

6. The resources present at the asteroid will aid to complete funding of the project and leave us in a win-win position (if it initiates according to the plans).

Further below, we are going to explain in detail each parts of our space station which covers every nook and cranny of our space station and will help better understand the functionality of our space station.
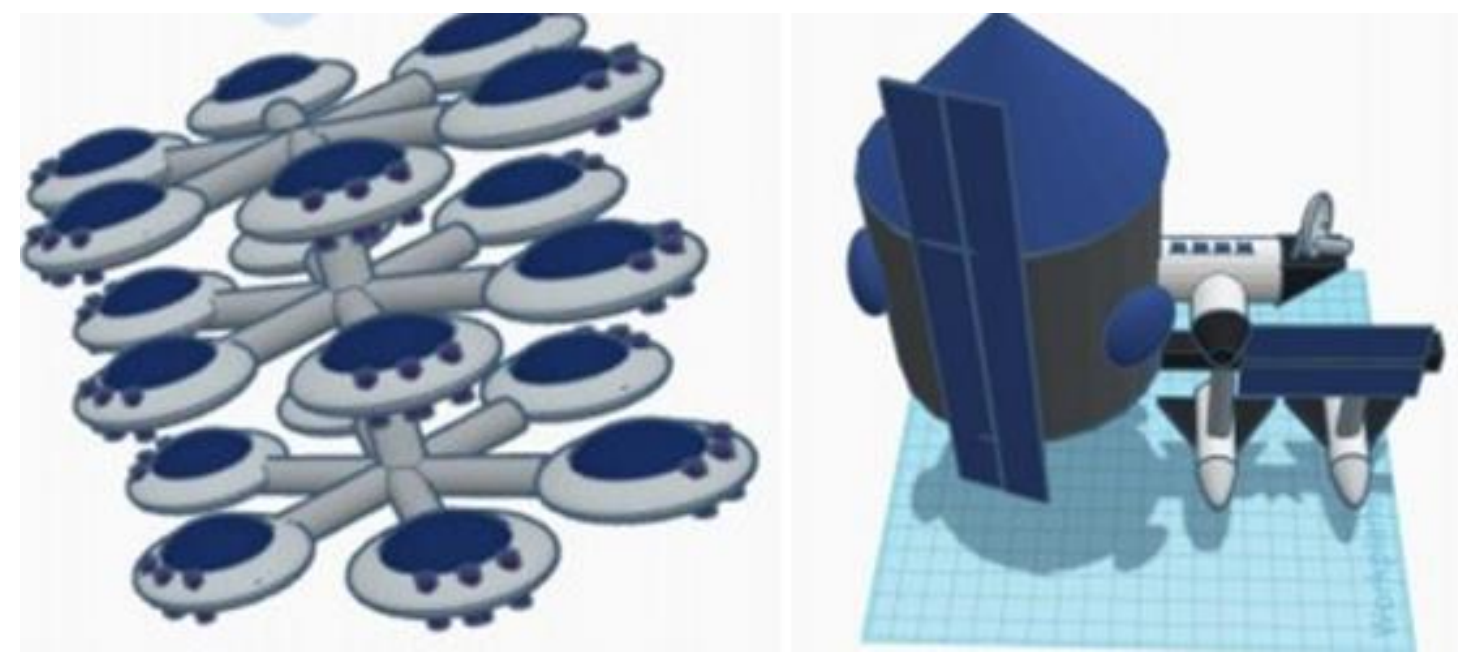

The front view of our space station the inside view of our space station

\section{DETAILED ANALYSIS OF EACH PART OF SPACE STATION}

\section{The control room}

The control room of the space station is located below the main monitoring radar. It will consist of a staff of flight controllers and other personnel who will monitor movements, distant objects approaching and other tasks using telemetry. There will be a separate team for individual subtasks with different time slots including altitude control system, power propulsion, thermal orbital operation, altitude dynamics. Other than that there will also be a team monitoring corridors, living spaces, lifts and space stations other places within the control room via telecoms and surveillance cameras installed for security purposes. 
In cases of emergencies, the control room can issue a warning that will reach each individual person onboard on his smart watch so that they can reach the individual capsule and near the closest safest spot as soon as possible and any casualties can be avoided.

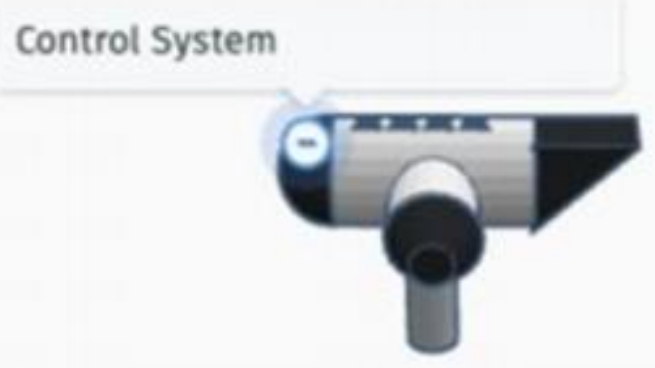

\section{Power Station}

One of the most effective ways to generate energy up there is using the most prominent source of energy present free i.e solar energy from the Sun.

The space station has solar arrays which convert the Sun's energy intoelectricity that powers the spacecraft.

The electricity generated in the power station from the solar panels charges the viable connectors present in the space station. These batteries can power the space station even when it moves out of direct sunlight.

Space stations while travelling away from the sun will face large arrays of solar cells towards the side of the sun. This will obtain energy and will be used fortravelling until we reach the location.

For example, NASA's Juno spacecraft uses solar power all the way out at Jupiter, where it orbits the planet.

\section{ENERGY FROM BATTERIES}

In our space station we have also used some large sized batteries in order to keep a backup for power supply, in case the solar panels don't work, until the station getshelp from earth. Space station batteries are designed to be durable with the introduction of hints of titanium.

To make the outer surface more strengthened, parts of plastic have also been used as complex structures of them combined with high tensile strength metals make it almost durable to each kind of environment. 


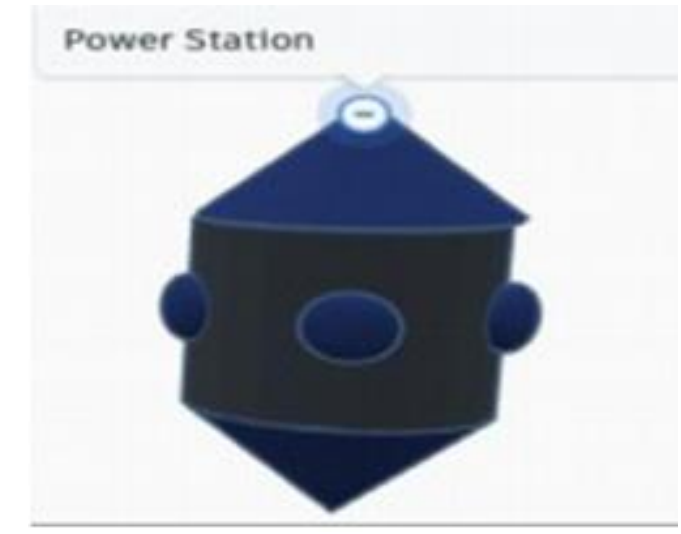

\section{ENERGY FROM ATOMS}

Some atoms - called radioisotopes - are unstable and begin to fall apart. As theatoms fall apart, they release energy as heat. A radioisotope power system uses the temperature difference between the heat from the unstable atoms and the cold of space to produce electricity.

Such types of systems have already been used to power many missions. Forexample, it has powered missions to Saturn, Pluto and even spacecraft that have traveled to interstellar space. This type ofpower system also provides the energy for the Curiosity rover on Mars.

Radioisotope systems produce power for a very long time, even in harsh environments. In fact, NASA's two Voyager spacecraft use this type of power. They have traveled farther than any other human-made object and are still sending back information after more than 40 years in space!

\section{Radar}

The rover's downlink sessions (when the rover sends information back to Earth) are generally roughly 15 minutes each, with usually two downlink sessions per relay orbiter (ODY, MRO) per Martian day (sol), which are usually about the path the space station is following and updates on the working of the spacecraft, while the signals sent from the earth will also ensure whether the journey the spacecraft is following has any challenges ahead while also informing about any potential findings that can be utilized, the location of the radar on the spaceship is just over the control room of the spacecraft. 


\section{Solar Arrays}

The solar arrays in the space station are installed in front of the common corridorand at the front side of the outer shell of the spaceship.

A solar array starts with solar cells - or photovoltaic cells - which are then groupedtogether to make solar panels. This group of solar panels is called an array. There are a total of 8 solar arrays installed in the spaceship and are used to convert lightreceived from the sun to electricity and will be utilized as the main source of electricity in the spaceship. Since there are a total of 144 panels in each array which comes out to be 1152 solar panels in total.

Since the solar panels use photovoltaic system the amount of energy converted bya single solar panel annually can be derived by a formula i.e $\mathrm{E}=\mathrm{A} * \mathrm{r} * \mathrm{H} * \mathrm{PR}$ where Eis energy ,A is total area $\left(\mathrm{m}^{\wedge} 2\right) \mathrm{r}$ is solar panel yield $(\%), \mathrm{H}$ is the annual average solar radiation on tilted panels and $\mathrm{PR}=$ performance ratio.

We can calculate the energy yielded by the solar panels.
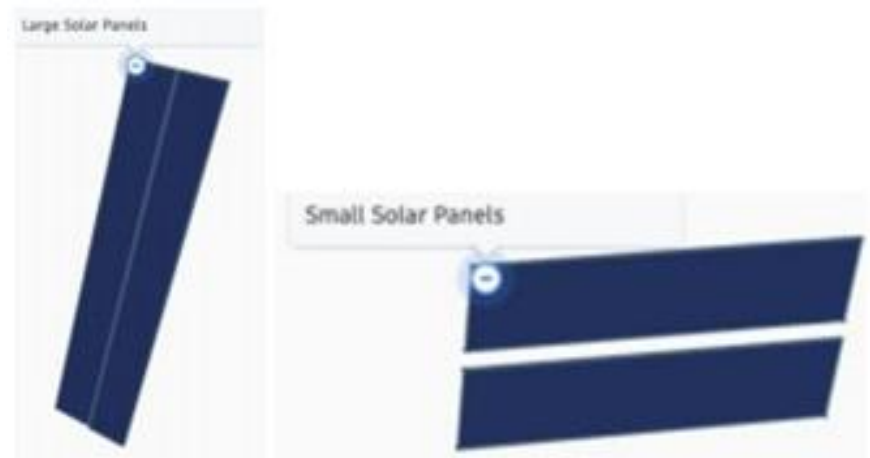

\section{Pods}

Space pods are one of the most vital parts of the space station. They are used in cases of emergency and even for the purposes where the entire craft can't go, for example, mining.

Space Pods are the station's pilotable support craft, capable of holding two pilots, anumber of passengers depending on the pod's armor. Hence, the design of the space pod plays a very important role. The space pods in our space station have agreat mechanism which supports the defense system as well as the emergency system too.

When we travel in space we don't know what object we may encounter so that'swhy it's really important to have a good defense system so that the pilot can instantly shoot that object and can move forward. 
International Journal of Social Science and Economic Research

ISSN: 2455-8834

Volume:06, Issue:07 "July 2021"

\section{TYPES OF PODS}

The pods with bigger size may occupy an area up to 2 tiles of space. Their size has both benefits and drawbacks. These pods tend to have more strength than theminiputts. At the same time, their larger size makes them unable to navigate narrow gaps and easier to hit, and they tend to be slower than their Miniputts.

\section{Miniputts}

Miniputts use the same armor plating as the larger pods, and can be upgraded with the same components. They are very fast in speed although they lack thehealth capacity.

\section{Lodging and accommodation}

Allocation for lodging and accommodation is equally important as it is for research and space exploration. Therefore the presented design structure has taken full care of the mentioned facilities to a great extent.

The structure is divided into 16 inner lodging stations known as Accomopod.They are located on the geometrically upper half of the main station.

Each accomopod accumulates as much as $-\mathrm{XI}$ people at once and comprises of 4 bathrooms and ample amount of place to relax. There is a self-operated kitchen attached to each pod.

Safety devices are installed in each pod and are present at every 20 meters. The kitchen comprises space for 6 people at a time standing and preparing food. The bathrooms are supplied with the necessary amount of water supply.

4 Accomopods together make a mega group and the resources are allocated in 4quarters for the 4 mega groups. The distribution of resources is controlled by the trend and rate of consumption of resources done by them. Along with this weeklyreport of resources used and warnings if more resources are being used or called off are dealt with the trends and statistical data stored at the control room.

The lobbying area serves as a common path for each pod and processes the means of communication to and fro easily.

It has cellular circular walls made of alloys of aluminum and a combination of ferrous and copper.

The branched network joining the accomopods meets at a common place knownas the transferor which is a mode of transportation of both resources and humans. 
International Journal of Social Science and Economic Research

ISSN: 2455-8834

Volume:06, Issue:07 "July 2021"

\section{The transportation tube}

One of the major roles are being overprotected and sustained by allowances of titanium, ferrous, copper. It is primarily being used as a media to interlink resources, power stations with the agriculture segment. However the use is not limited to this, it also acts as the medium of transport of tools and machinery fromthe agriculture site to the asteroid site for mining.

The agriculture segment disjoints partially for some time and makes way for thetools to transport from the tube to the site.

After the transportation of the tools, the disjoint agriculture segment joints backand this happens using hydraulic and other air pressure junctions.

After this, the tools are transported back via the same process and we have enough energy harvested to initiate this process every once in 24 earth hours.

\section{AGRICULTURE, ECOSYSTEM AND WASTE MANAGEMENT}

1. Space farming- It refers to crop cultivation for food in space which is equivalentto agriculture.

2 Need of agriculture-

- Plants can be used as food and can also provide a refreshing atmosphere.

- They are also helpful in metabolizing carbon dioxide and converting it intooxygen.

- Plants also help in controlling cabin humidity.

- Plants can also offer a psychological benefit to the people in the station.

3. Challenges to Space Farming-

- Insufficient Gravity and its effect on root development.

- Providing an appropriate amount of light and nutrients.

Now that we have discussed the importance and the challenges that come along with Space farming, we can look into how we are going to impose this in the spacestation. Since the lower levels from level 1 to level 4 which constitute the lower cone are dedicated to agriculture, we have more than enough area to satisfy the needs of every passenger on board. For the insufficient gravity since the space station will already have the necessary gravity, this will help in efficient agriculture on board. 


\section{International Journal of Social Science and Economic Research}

ISSN: $2455-8834$

Volume:06, Issue:07 "July 2021"

Coming to providing water and necessary nutrients to the plant, since the light from sun would be sufficient, we can just have the lower cone built in such a way that it is in direct contact of light hence resolving the issue of light deficiency.

For water, since the station is located near asteroid 16 Psyche. Because of itsample resources of water, we will not face any issues with the scarcity of water; this water will also be helpful in generatingOxygen with the help of electrolysis.

The major crop nutrients are nitrogen, phosphorus and potassium. As we have already explained in our waste management system, we will use the waste as organic manure which will cover most of the nutrient requirements of the plants and the leftover requirements can be covered by the resources found on 16 Psyche.

In one of the allocated levels for agriculture we will also use the Vegetable Production System better known as Veggie. We will use it for growing foods like berries, tomatoes, peppers and other antioxidant rich food that would provide an added plus that is protection from space radiations.

The passengers will have to shift to a vegan based lifestyle as rearing of animals would be difficult in space. So as to maintain a healthy diet we need a balanced diet between carbohydrates, fibers, fats, proteins and micronutrients. Therefore, we will have crops such as rice, wheat, potato, sweet potato, soybean and legumes.

\begin{tabular}{|l|l|}
\hline Nutrient & DV \\
\hline Fat & $78 \mathrm{~g}$ \\
\hline Saturated Fatty acid & $20 \mathrm{~g}$ \\
\hline Cholesterol & $300 \mathrm{mg}$ \\
\hline Sodium & $2300 \mathrm{mg}$ \\
\hline Potassium & $4700 \mathrm{mg}$ \\
\hline Carbohydrates & $275 \mathrm{~g}$ \\
\hline Added Sugars & $50 \mathrm{~g}$ \\
\hline Dietary Fibres & $28 \mathrm{~g}$ \\
\hline Proteins & $50 \mathrm{~g}$ \\
\hline
\end{tabular}


International Journal of Social Science and Economic Research

ISSN: 2455-8834

Volume:06, Issue:07 "July 2021"

Wheat: Major Nutrients- $25 \mathrm{~kg}$ Nitrogen $(\mathrm{N})$ are required per ton of grain containing 15 percent protein in a temperate environment. $1 \mathrm{~kg}$ of $\mathrm{N}$ produces about $15-25 \mathrm{kgof}$ grain. For high yields, an optimal supply of Phosphorus (P) and Potassium (K) are required. For a yield of 8 ton/ha around $90 \mathrm{~kg} / \mathrm{ha} \mathrm{P} 2 \mathrm{O} 5,160 \mathrm{~kg} / \mathrm{ha} \mathrm{K} 2 \mathrm{O}$ and $25 \mathrm{~kg} / \mathrm{ha} \mathrm{Mg}$ is required. In addition to these macronutrients some micronutrients like $\mathrm{Mn}$ and $\mathrm{Zn}$ are also needed.

Rice: Major Nutrients- The macronutrients needed to produce rice or paddy includes macronutrients such as N, P, K and some micronutrients such as Calcium , Magnesium, Manganese, Zinc , Copper, Boron, Molybdenum, Silicon, and Sulphur. In order to produce 1 tonne of paddy, the crop absorbs an average of $20 \mathrm{~kg} \mathrm{~N}, 11 \mathrm{~kg}$ P2O5, $30 \mathrm{~kg} \mathrm{~K} 2 \mathrm{O}, 3 \mathrm{~kg} \mathrm{~S}, 7 \mathrm{~kg}$ $\mathrm{Ca}, 3 \mathrm{~kg} \mathrm{Mg}, 675 \mathrm{~g} \mathrm{Mn}, 150 \mathrm{~g} \mathrm{Fe}, 40 \mathrm{~g} \mathrm{Zn}, 18 \mathrm{~g} \mathrm{Cu}, 15 \mathrm{~g} \mathrm{~B}, 2 \mathrm{~g}$ Mo and $52 \mathrm{~kg} \mathrm{Si}$. Generally, $1 \mathrm{~kg}$ of $\mathrm{N}$ is required for $20 \mathrm{~kg}$ or more yield of rice. Around $40-80 \mathrm{~kg}$ of P2O5/ha and $60 \mathrm{~kg}$ $\mathrm{K} 2 \mathrm{O} /$ ha is required for the higher yields of the crop.

\section{Legumes}

Chickpea Major Nutrients- It is a rich source of proteins and contains about $20 \%$ protein in it . It also benefits the soil by Rhizobium inoculation as it helps to augment $\mathrm{N}$ supply by the soil. It requires around $15-20 \mathrm{~kg} \mathrm{~N} / \mathrm{ha}$ and $0-50 \mathrm{~kg}$ P2O5/ha. We can also use $20-30 \mathrm{~kg}$ sulphur/ha to significantly improve the yield.

Soybeans Major Nutrients - It is a very energy-rich grain legume containing 40 percent protein and 19 percent oil in the seeds. It also helps in rhizobium inoculation. Even though nitrogen fixation helps in nourishing the soil, a starter dose of $20-40 \mathrm{~kg}$ of $\mathrm{N} / \mathrm{ha}$ is required so that the rhizobium nodes could develop. For soil type such as on the station with low nutrients, 50-70 kg $\mathrm{P} 2 \mathrm{O} 5 / \mathrm{ha}$ and $60-100 \mathrm{~kg} \mathrm{~K} 2 \mathrm{O} / \mathrm{ha}$ are required. In addition to these macronutrients some micronutrients like $\mathrm{Zn}$ and $\mathrm{Mn}$ are also required based on the soil quality.

Potatoes Major Nutrients- Even though $\mathrm{N}$ application promotes early development of the foliage, excess of it can delay tuber initiation. Since we will be using organic manure the requirements for $\mathrm{N}$ fertilizer is $40-50 \mathrm{~kg} / \mathrm{ha}$. $\mathrm{P}$ requirement can be in the range of 100 to 300 $\mathrm{kg} / \mathrm{ha} \mathrm{P} 2 \mathrm{O} 5$ depending on soil $\mathrm{P}$ status. Fertilizer $\mathrm{K}$ requirement depends on soil type and organic manure application. Therefore K recommendations range from 60 to $300 \mathrm{~kg} \mathrm{~K} 2 \mathrm{O} / \mathrm{ha}$.

Sweet Potatoes Major Nutrients- It is usually recommended to use around $50 \mathrm{~kg} \mathrm{~N} / \mathrm{ha}, 50 \mathrm{~kg}$ $\mathrm{P} 2 \mathrm{O} 5 / \mathrm{ha}$ and $80-120 \mathrm{~kg} \mathrm{~K} 2 \mathrm{O} / \mathrm{ha}$. Even though we are generally only going to use organic manure, due to lack of fertilizers, to bump up the nutritional content we can also use some fertilizers. We can do farming in three ways: (1) Only manure, (2) Only fertilizers and (3) Both manure and fertilizers, third one being the most beneficial. The above mentioned fertilizer 
amount varies with the content of manure in them and is indirectly proportional to it. The amounts are provided for temperate climate.

For rich soil we are also going to practice crop rotation and will provide special climates to each type of crop for better yields.

\section{Ecosystems in space}

Humans have basic needs for food, water, air, and shelter (constituting an ecosystem).

Ecosystems within Earth's biosphere provide for these needs. In our space settlement, we are developing ways to support living away from Earth for long periods of time. Our space settlement is designed to meet such needs.

\section{Other factors required to achieve:}

A space settlement, first of all, needs a good and safe living environment for the people. Our settlement has good living quarters (connected to each other)for the people to live with enough $\mathrm{O} 2$ in the air .

Then, a space settlement requires arrangement for people's food requirements, which is satisfied by agriculture and taming of various crops and animals. The necessary raw materials and tools will be taken to space to take care of agriculture and carry out all the processes afterwards.

Domestic animals can also be taken to space for taming and other dairy products can be obtained from them which can also contribute to food requirements.

Plants can be started growing on earth and can then grow progressively as we launch our space settlement in space. Then we have oxygen initially at the start. We can then separate the agricultural land from the vacuum and create an artificial atmosphere.

Then we will have enough $\mathrm{O} 2$ and $\mathrm{CO} 2$ for animal and plant needs .We can also form oxygen and water from each other so that all basic necessities are satisfied. The plants cultivated above will start growing with basic available requirements and then later on the plants will help in producing oxygen and carbon dioxide which will further help in making an ecosystem and help in carrying out other processes.

Next, we have the very important chemical cycles $\left(\mathrm{H}_{2} \mathbf{O}, \mathrm{O}_{2}\right.$ and $\left.\mathrm{CO}_{2}\right)$. Theseare necessary for obtaining clean water and fresh air for people in the settlement. Water should be prepared using combining hydrogen and oxygen atoms to produce it at large scale. 


\section{International Journal of Social Science and Economic Research}

ISSN: $2455-8834$

Volume:06, Issue:07 "July 2021"

The carbon cycle begins with atmospheric carbon dioxide. During photosynthesis producers convert atmospheric carbon dioxide and water into glucose and oxygen. Plants, as well as animals, use glucose in respiration to provide energy. Respiration combines glucose and oxygen to produce high-energy molecules (ATP) and carbon dioxide and water as waste.

The next thing is garbage disposal. Garbage will always be generated and willhave to be taken care of. So the natural waste (that is produced by animal and human waste) can be reused in agriculture as manure and fertilizer and it can be put in soil to provide nutrients.

Food waste can also be reused this way as it is biodegradable. Other types of waste (such as machinery waste, plastic waste) pose a problem on how to be disposed of. Common types of garbage disposal methods are through landfills and incineration. Since landfills cannot be practically created and incineration is not possible as it can be harmful for the settlement.

So the best way to destroy wastes is the process of plasma gasification . It is the process of waste disposal that will prevail in the future and will replace landfill systems.

Plasma gasification is an emerging technology which can process landfill waste to extract commodity recyclables and convert carbon-based materials into fuels. It can form an integral component in a system to achieve zero-waste and produce renewable fuels, whilst caring for the environment.

Plasma arc processing has been used for years to treat hazardous waste, such as incinerator ash and chemical weapons, and convert them into non-hazardous slag.

Plasma gasification is a multi-stage process which starts with feed inputs ranging from waste to coal to plant matter, and can include hazardous wastes. The first step is to process the feedstock to make it uniform and dry, and have the valuable recyclables sorted out.

The second step is gasification, where extreme heat from the plasma torches is applied inside a sealed, air-controlled reactor. During gasification, carbon-based materials break down into gases and the inorganic materials melt into liquid slag which is poured off and cooled. The heat causes hazards and poisons to be completely destroyed.

The third stage is gas clean-up and heat recovery, where the gases are scrubbed ofimpurities to form clean fuel, and heat exchangers recycle the heat back into the system as steam. The final stage is fuel production. The output can range from electricity to a variety of fuels as well as chemicals, hydrogen and polymers.

The syngas produced here is very useful and can be of great help altogether. 
International Journal of Social Science and Economic Research

ISSN: 2455-8834

Volume:06, Issue:07 "July 2021"

\section{SPACE MINING}

For any civilization to exist and flourish in the space settlement, we will need resources and raw materials for it. By resources, we mean minerals and metals. Though, if we carry enough resources to space, we will still need more and more. This can be accomplished through asteroid mining. Our space settlement as you already know is orbiting the famous, M type asteroid, $\mathbf{1 6}$ Psyche.

One of the most intriguing targets in the main asteroid belt, 16 Psyche is a giant metal asteroid, about three times farther away from the Sun than is the Earth. Its average diameter is about 140 miles (226 kilometers) - about one-sixteenth the diameter of Earth's Moon or about the distance between Los Angeles and San Diego.

Unlike most other asteroids that are rocky or icy bodies, scientists think the M-type (metallic) asteroid 16 Psyche is comprised mostly of metallic iron and nickel similar to Earth's core.16 Psyche is a massive asteroid that is particularly interestingdue to its metallic composition, which has caused some people to speculate about its potential value. In fact, due to all the metal it contains, some are reporting that it could be worth up to $\$ 700$ quintillion.

Also as you can see there are two space-shuttles in our space settlement that are mainly placed to carry out mining on the asteroid while the space settlement is orbiting it.

Psyche is shaped somewhat like a potato. Observations indicate that its dimensionsare 173 miles by 144 miles, by 117 miles (that's 279, 232, and 189 kilometers, respectively).Psyche orbits the Sun between the orbits of Mars and Jupiter at a distance ranging from 235 million to 309 million miles (378 million to 497 million kilometers) from the Sun. That's 2.5 to 3.3 Astronomical Units (AU).

Psyche is massive enough that its gravitational perturbations on other asteroids canbe observed, which enables a mass measurement. The values for the mass of $(3.38 \pm 0.28) \times 10^{-11} \mathrm{M}$. Due to its large size a lot of area can be used for mining which gives more possibility of faster mining of minerals .

The mining of the metals will be done in a few steps. First would be the shuttles to travel to the surface of psyche 16. Then we will have to dig the surface of the asteroid. Quarrying and extraction tools will be taken along in the manned shuttles. With the help of people and good machinery, the minerals line iron, nickel,and gold can be extracted. 
International Journal of Social Science and Economic Research

ISSN: 2455-8834

Volume:06, Issue:07 "July 2021"

We may face another problem by its surface gravity and density change because rigorous extraction may undermine the surface. So its large size will help in maintaining uniformity and will support centuries of years in mining without major problems.

Then our next step will be loading all the minerals and transporting them back to the main space settlement so that it can be used and stored as per required. It won't take more thrusting force to go back to orbiting the asteroid from its surface as it only has a gravity of $0.06 \mathrm{~m} / \mathrm{s} 2$ which is like $3 \%$ of the gravitational force of moon, hence there will not be much problem in travelling from the space settlement to the surface back and forth .

\section{TRANSPORTATION AND TECH}

Space mining not only requires resources to be mined for. But implementation and implantation of tools and mechanics required for space mining is adequately important.

Certain things need to be taken into consideration before moving forward with the idea of mining.

1. First of all, we need an orbital transportation Hub or a space station for that matter to carry out the machinery and tools to longer distances for more duration of time. We already have the structural design for the transportation of tools and resources.

2. A connected space fuel depot is required for interlinking of resources with the space station so that the extracted resources can be harvested to gain energy and the resources obtained can be further and preserved (if needed) for further research and analysis.

3. There's a good possibility that we may find certain rocks, resources and matter that may not be identified by the people present there at the space station or they don't possess the technical know-how at the moment to make use of it. Therefore, a communication relay is required to transmit data readings and reports of materials being found over the period of time back to Earth.-Planetary Resources is developing a system under contract with NASA and that technology with time will help in further transmission of data from the space station to Earth.

4. For a more convenient system of space mining, we don't require to dig deep holes, miles etc. to gain metal supplies and resources. There's a technique known as Magnetic raking which by placing a magnet on each prong of a rake loose the asteroid soil popularly known as the regolith and can be used as a media to take metals from there.

5. More and more ways can be developed in order to extract metal and water from the 


\section{International Journal of Social Science and Economic Research}

ISSN: $2455-8834$

Volume:06, Issue:07 "July 2021"

comparatively low gravity hold asteroids. But a decade old vibrational technique is as efficient as it sounds to be for the purpose. The asteroid soil is shaken through a sieve to separate the particles that could be burnt more effectively in an oven. This technique is also valid in zero-g. The already loosenedsoil by magnetic raking makes it even easier to extract the required particles.

6. With almost no gravity on asteroids, it isn't easy to land on. The NASA's propulsion laboratory is set to develop steel -toenails to land comfortably. But this makes the rise of another important concept, how will we create artificial gravity up there?

The next following pages will guide us about the process as to how we canachieve that.

\section{ARTIFICIAL GRAVITY}

Artificial gravity is the creation of a force which is similar to the force of Gravity, by rotation. Hence, Artificial Gravity is similar to centrifugal force in a rotating frame of reference. We can also say that Artificial Gravity may also refer to the effect of linear acceleration, e.g. by means of a rocket engine.

How can we create it?

Artificial gravity can be created using a centripetal force. The centripetal force is required by a body to move in a circular path. For the rotation of the space-craft it is the normal force which is provided by Space-craft's hull -acting as centripetal force.

Artificial Gravity can be created by providing a rotation system. Rotation produces the same effect as gravity because it produces the same force as gravity. We can create a force outside the walls which is equal to the force of gravity.

When the space station is spanned it produces a force which makes you feel a squeeze force against the sides. All the members become glued to the walls and then they drop the floor out. None of the members falls on ground because they are being held by the force of rotation.

In a rotating space station, people will be "stuck" to the outside too, but with a force equal to that of gravity so they will be able to walk around on the edges. The force will be the same all around the outside of the rotating cylinder, so depending on the design it could look like people are living on the ceiling!

The gravity of the people around you in the space station will make a negligible difference only. Though it is true that objects which have mass exert a gravitational force on each other, unless 
International Journal of Social Science and Economic Research

ISSN: 2455-8834

Volume:06, Issue:07 "July 2021"

the mass is very large and it has little effect. The people on the Space Station cannot change the artificial gravity on the space station just like they cannot do it on earth.

Our Space Station supports a great system of Artificial Gravity and it would help all the astronauts to work effectively and maintain the space station properly.

\section{STORAGE}

We will have separate compartments for research purposes and storage. Once the resources will come from the asteroid and get purified for use, different resources will go to their respective areas.

When the water from the asteroid is mined, it will be purified and then it will be supplied to the storage area for use by the people in living quarters and the personnel. It will also be transported to the hydel energy plant for power generation and will also be transported to the lower cone for agricultural purposes.

While these resources will be majorly utilized for the people on board some part will also be experimented on and be used for comparison between the resources found on earth. The studies would be shared with scientists on earth.

While the storage area which will be on one level will be dedicated for the resources from the asteroid, another level will be dedicated for the storage of different products produced in the station itself. Like for the agricultural produce, we would have small silos and refrigerated areas for different vegetables.

\section{CONCLUSION}

The main purpose of the research paper Saurayuthah Settlement is to find a space settlement outside earth and lay some reasonable arguments and proofs in order to give a layout of how this could actually be possible.

One condition we had to follow was that a planet cannot be chosen as a settlement place and thus after hours of research the location around which the settlement was to be set-up was finalised and thus 16 psyche was chosen which is an M-type asteroid placed between Mars and Jupiter, the asteroid is predominantly metal including precious metals as well as adequate amounts of water. Metals such as platinum, gold and others such as nickel, iron. The asteroid 370 million $\mathrm{km}$ away fromearth has enough iron to fill the whole city of Manhattan and is estimated to be around \$10 Quadrillion which is more than whole economy of earth, although the information on its full composition is to be revealed by the year 2022.After this a prototype of the Space settlement station was needed which took several factors in consideration such as, self-sustainability 
International Journal of Social Science and Economic Research

ISSN: 2455-8834

Volume:06, Issue:07 "July 2021"

,agriculture and mining provisions, Lodging and accommodation of over 500 people and staff members, Pre-installed emergency/search out pods for space exploration and mining search not only restricted to nearby places, A direct approach to sources present at the asteroid will aid to complete funding of the project and leave us in a win-win position.

Next up we had to set-up an artificial ecosystem in the space station and also a garbage disposal system where we used the plasma gasification method. It is the process of waste disposal that will prevail in the the future and will replace landfill systems. Another thing necessary to prevail life form outside earth is the process of space mining which for any civilization to exist and flourish in the space settlement isextremely necessary. Unlike most other asteroids that are rocky or icy bodies, scientists think the M-type (metallic) asteroid 16 Psyche is comprised mostly of metallic iron and nickel similar to Earth's core.16 Psyche is a massive asteroid that isparticularly interesting due to its metallic composition, which has caused some people to speculate about its potential value. In fact, due to all the metal it contains, some are reporting that it could be worth up to $\$ 700$ quintillion.

Another thing is the process of storage of all the goods that are mined/brought from earth before the start of the journey. Artificial gravity is the creation of a force which issimilar to the force of Gravity, by rotation. Hence, Artificial Gravity is similar to centrifugal force in a rotating frame of reference. We can also say that Artificial Gravity may also refer to the effect of linear acceleration, e.g. by means of a rocket engine. These processes sum up in short our reasons and how to's to set up a space settlement outside our home planet.

\section{ACKNOWLEDGMENT}

I take this opportunity to express my profound gratitude and deep regards to my peers Gopesh Bajaj , Vatsal Gupta , Shivank Kapur and Kanav Goyal for their help and constant encouragement throughout the course of this project. The blessing, help and encouragement given by them from time to time shall carry me a long way in the journey of life on which I am about to embark.

\section{BIBLIOGRAPHY}

a0443e04.pdf (fao.org)

Britannica , Spacecraft, Written by editors of The Editors of Encyclopaedia Brittanica curious.astro.cornell.edu , by Ryan Anderson, last updated on June 22,2015

Hooper L, Abdelhamid A, Bunn D, Brown T, Summerbell CD, Skeaff CM. Effects oftotal fat intake on body weight. Cochrane Database Syst Rev. 2015; (8):CD011834. 
International Journal of Social Science and Economic Research

ISSN: 2455-8834

Volume:06, Issue:07 "July 2021"

Manafacturing.net, Asteroid mining could solve rare metal shortage, Jan $31^{\text {st }} 2020$

MY MODERN MET, NASA Is Going to Visit a Gold and Precious Metal AsteroidWorth \$700 Quintillion, By Jessica Stewart on July 232019

Medium.com , Recycling Organic Waste for Fertilizer, by Whirlston , Jan 11 , 2018 NASA, Published Jan 112021 , Editor: Mark Garcia

NASA Science $\quad$ solar system exploration,16 Psyche, $\quad$ Credit: Maxar/ASU/P.Rubin/NASA/JPL-Caltech

NASA Science, Space Place, Explore earth and SpaceNASA TV , Credits: NASA/Cory Huston

Popular Mechanics, The Technology we'll need to mine Asteroids, By MichaelBelfiore, Aug 16, 2012

Statista , The Colossal Untapped Value of Asteroids by Martin Armstrong , Jun 30 ,2020

Treehugger, By Kristan Bobst, Updated on 23 April 2018 